\title{
Comparison of the clinical application of reactive oxygen species and inflammatory markers in patients with endocarditis
}

\author{
Stanisław Ostrowski', Anna Marcinkiewicz², Dariusz Nowak ${ }^{3}$, Radosław Zwoliński', Ryszard Jaszewski ${ }^{1}$
}

1Department of Cardiac Surgery, $1^{\text {st }}$ Chair of Cardiology and Cardiac Surgery, Medical University of Lodz, Poland

2 Medical student of the $5^{\text {th }}$ year, Medical University of Lodz, Poland

${ }^{3}$ Department of Clinical Physiology, Medical University of Lodz, Poland

Submitted: 6 March 2011

Accepted: 3 October 2011

Arch Med Sci 2012; 8, 2: 244-249

DOI: 10.5114 /aoms.2012.28551

Copyright @ 2012 Termedia \& Banach

\section{Abstract}

Introduction: Infective endocarditis (IE) is still connected with high operative mortality. Inflammatory markers are commonly used in monitoring patient clinical condition. Respiratory burst and reactive oxygen species (ROS) are the main way of pathogen elimination. Specificity of this process in the aspect of bacterial infection is the key for correlation assessment between ROS and inflammatory markers in patients with IE. In the study, assessment of ROS as a clinical indicator in IE was conducted.

Material and methods: During 2007/2008 in the Cardiosurgical Clinic of the Medical University in Lodz there were 20 patients operated on for IE. The examined population consisted of 13 men and 7 women, aged from 23 to 74 years. Inflammatory markers - leukocytosis (WBC), C-reactive protein (CRP), procalcitonin $(P C T)$ and erythrocyte sedimentation rate (ESR) - were assessed preoperatively, on the $3^{\text {rd }}, 7^{\text {th }}, 12^{\text {th }}$ and $21^{\text {st }}$ day. Simultaneously, with the second venous blood sample chemiluminescence (luminal enhanced whole blood chemiluminescence) was carried out and used to assess ROS production. The results were analyzed statistically.

Results: Positive correlation between ESR, CRP and ROS in the preoperative period was confirmed. An increase in ROS and a statistically significant increase in inflammatory markers on the $3^{\text {rd }}$ day were observed. The ROS normalized on the $12^{\text {th }}$ day. Marked individual variability was specific for the inflammatory markers. Despite the significant decrease, not all of them achieved a normal level at the last control point.

Conclusions: Assessment of ROS seems to be a universal parameter with possible application in patients with IE.

Key words: infective endocarditis, chemiluminescence, respiratory burst.

\section{Introduction}

Reactive oxygen species (ROS) released during the respiratory burst (RB) are the main protection from bacteria. Their impaired production as in staphylococcal endocarditis results in a severe course of the disease [1]. On the other hand, their uncontrolled generation in the ROS-induced ROSrelease mechanism (RIRR) plays a negative role [2]. Postoperatively, increased neutrophil activation due to secondary stimuli such as extracorporeal circulation (ECC) called 'priming' can be observed [3]. It is

\author{
Corresponding author: \\ Stanisław Ostrowski MD, PhD \\ Department \\ of Cardiac Surgery \\ $1^{\text {st }}$ Chair of Cardiology \\ and Cardiac Surgery \\ Medical University of Lodz \\ 4 Al. Kościuszki \\ 90-419 Lodz, Poland \\ Phone/fax: +48 426331558 \\ E-mail: stanislaw.ostrowski@ \\ umed.lodz.pl
}


expressed by postoperative neutrophilia and their increased capacity for aggregation as well as ROS production. Additionally, increasing levels of acute phase proteins during bacterial infection cause further ROS release [4]. Acute phase proteins, used commonly in treatment monitoring, are unspecific components of the immunological response. They take part in opsonization, complement activation and regulation of immunocompetitive cells, mainly leukocyte activation. Erythrocyte sedimentation rate (ESR) alterations in the course of endocarditis are the result of both plasma protein and cellular blood composition changes such as anemia or leukocytosis. So far, proposed schemes of treatment monitoring in patients with infective endocarditis (IE) have proved unsatisfactory due to lack of specificity of the laboratory parameters as well as difficulty in their interpretation. Researchers continue to seek a parameter that will give rapid responses about the indications for operation and effectiveness of treatment, especially in clinically difficult cases.

Aim of the study was establishing the possible clinical application of ROS in patients with IE; comparison with other commonly used inflammatory markers; the hypothetical usage of ROS level as an indicator in monitoring the treatment of patients operated on for IE.

\section{Material and methods}

The assessed population was composed of 20 patients with diagnosed IE, admitted to the Cardiosurgical Clinic of the Medical University in Lodz during 2007/2008 and subjected to the operation of endocardial vegetation removal. Patients were informed about the planned procedures and additional examinations. Written consent was obtained from the patients if the procedures were not considered as part of the standard cardiosurgical management. The study protocol was approved by the ethical committee of our institutions. The diagnosis of IE was established according to modified Duke's criteria [5]. The population consisted of 7 women and 13 men, aged from 23 to 74 years. The average age was 47.8. NYHA class III accounted for 11 patients (55\%). A scheduled operation of prosthetic valve implantation was conducted in 18 patients. In one case it was a reimplantation. Two patients were operated on due to life-threatening indications in an active phase of IE. The complete time of ECC ranged from $65 \mathrm{~min}$ to $158 \mathrm{~min}$ (average $105 \mathrm{~min}$ ). The cross clamp time varied from $48 \mathrm{~min}$ to $132 \mathrm{~min}$, average $81 \mathrm{~min}$. The heart was perfused with a cold crystalloid cardioplegic solution, given antegrade and non-continuously (from 800 to $1600 \mathrm{ml}$ ). Patients had venous blood collected and white blood cells (WBC), procalcitonin $(P C T), C$-reactive protein (CRP) and ESR levels were assessed at the control points: preoperatively and on the $3^{\text {rd }}, 7^{\text {th }}, 12^{\text {th }}$ and $21^{\text {st }}$ day after the operation. Simultaneously patients had LBCL carried out from $5 \mathrm{ml}$ venous blood samples collected in the morning. On the basis of this examination respiratory burst and ROS production by activated blood granulocytes (PMNs) and monocytes were determined. The test was conducted within $30 \mathrm{~min}$ from the blood collection. Nine hundred fourty-seven $\mu \mathrm{l}$ of luminal warmed to $37^{\circ} \mathrm{C}$ within $60 \mathrm{~min}$ was added to $3 \mu \mathrm{l}$ of blood. Samples were incubated at $37^{\circ} \mathrm{C}$ for $30 \mathrm{~min}$. Luminescence was measured during 1 min using a 1251 luminometer (Bio-Orbit, Turku, Finland). After adding $50 \mu$ l of formyl-methionylleucyl-phenylalanine (fMLP) the measurement was continued for the next $7 \mathrm{~min}$. The measurements were repeated 4 times for each patient and the average value was calculated. Resting chemiluminescence was given in aU/10 4 phagocytes (PMNs and monocytes present in assessed sample) and fMLP-stimulated total chemiluminescence $(\mathrm{tCL})$ in $\mathrm{aU} \times \mathrm{s} / 10^{4}$ phagocytes. Peak chemiluminescence $(\mathrm{pCL})$ and peak time were also recorded (respectively presented in $\mathrm{aU}$ and $\mathrm{s}$ ).

\section{Statistical analysis}

Data were analyzed statistically. Values were expressed as mean with standard deviation and median with range. Spearman test was used to determined the correlation between ROS production and particular inflammatory markers. The differences between chosen dependent variables were analyzed by the Wilcoxon test. ANOVA Friedman test with appropriate 'post-hoc' tests was used for assessing the parameters' variability with time.

\section{Results}

Only one case of endocarditis was related to a prosthetic valve. Preoperatively, Staphylococcus as an etiological factor was estimated in $50 \%$ of positive blood cultures. Fifty-five percent of all preoperative cultures were negative.

In the study a variable connection between the particular assessed inflammatory markers and ROS generation was found. A positive correlation was found only between ROS and preoperative levels of CRP and ESR (level of significance $p<0.05$ ). Leukocytosis correlated positively with $\mathrm{tCL}$ at the initial control point and with peak time on the $7^{\text {th }}$ postoperative day. Surprisingly, there was no correlation between ROS and PCT.

Although ROS level increased on the $3^{\text {rd }}$ postoperative day, it was not statistically significant. However, during the 21-day observation rCL, tCL and $\mathrm{pCL}$ started to decrease from the $3^{\text {rd }}$ day. On the $21^{\text {st }}$ day it reached the value before the operation. On the $12^{\text {th }}$ day a statistically significant $(p<0.05)$ 
decrease was noted. The difference between the level of ROS on the $7^{\text {th }}$ day and at subsequent check points was statistically significant $(p<0.05)$. The comparison between preoperative and postoperative peak time showed a statistically significant increase $(p<0.05)$.

The analysis of WBC, CRP, ESR and PCT revealed the highest increase of their values on the $3^{\text {rd }}$ day. At the subsequent control points a gradual decrease of their levels was observed. For all these parameters the differences were statistically significant $(p<0.05$ for PCT and WBC, $p<0.02$ for ESR, $p<0.0001$ for CRP). Furthermore, individual variability of the particular inflammatory parameters' normalization in the examined population was estimated. A statistically significant positive correlation between the preoperative values of CRP and remaining inflammatory markers was noted (Table I).

\section{Discussion}

The cardiosurgical operation of a patient with IE is a model example of a slight balance between contrary immunological mechanisms. Simultaneously, as a result of surgery and ECC usage, the systemic inflammatory response syndrome (SIRS) develops and stimulates the compensatory antiinflammatory response syndrome (CARS). Additionally, the presence of a restricted bacterial focus modifies the patient's response to the surgical trauma.

In comparison to the preoperative values, neutrophilia and lymphopenia, which tend to normalize within the next few days, can be observed [6]. The postoperative lymphopenia, caused by surgeryinduced lymphocyte apoptosis, is mainly responsible for the increased organism susceptibility to infection. It is especially significant in patients with IE [7].

Fransen et al. [8] assessed PMN activation by evaluating the level of bactericidal permeability increasing protein $(\mathrm{BPI})$ in patients subjected to CABG with or without ECC. Only in the first group did $\mathrm{BPI}$ remain elevated and the increase occurred during the aortic cross clamping. On the other hand, Tarnok et al. [9] recorded decreased activation of neutrophils during cardiosurgical operations in children. It was proven by decreased expression of the adhesive molecules (LFA-1, Mac-1) and reduced respiratory burst, both basal and PMA-stimulated
(PMA - phorbol-12-myristate-13-acetate). The researchers explained this effect by selective filtration of PMNs with increased adhesion capacity and their maintenance in the cardiopulmonary bypass (CPB) device or lung capillaries. Our experience and results confirm that the surgical procedure induces neutrophil activation, oxidative burst in phagocytes and ROS generation. However, a rapid decrease of $\mathrm{ROS}$ in the early postoperative period ( $\mathrm{rCL}, \mathrm{tCL}, \mathrm{pCL}$ ) is a sign of an effective cardiosurgical intervention and uncomplicated recovery. Appropriate antibiotic therapy was also proven to enhance the respiratory burst of neutrophils impaired during general infections in neonates [10]. Consequently, the antibiotic therapy in our patients was effective.

Although the prolongation of postoperative peak time in comparison to preoperative values was observed on the $3^{\text {rd }}$ day, only the difference with the postoperative values from the $21^{\text {st }}$ day was statistically significant. This may be related to impairment of the respiratory burst, probably in the mechanism of exhaustion. This state may be connected with increased susceptibility to recurrence of the infection. In cases of high risk patients or with worse prognosis, antibiotic therapy modification in this period should be considered.

Monocyte suppression (lack of TNF- $\alpha$ release and HLA-DR expression) may be a result of extensive surgery. Grundmann et al. [11] discovered that ex vivo monocyte blockade can be achieved with blood from patients after CABG and returned by adding anti-IL-10 and labetalol. Volk et al. [12] eliminated catecholamine and cortisol stimulated IL-10 production by applying the thoracic epidural block (TEB). However, they did not obtain elevation in monocyte activation. Hiesmayr et al. [13] observed the increase of IL-10 only in cardiosurgical patients in comparison to patients who underwent thoracic surgery. Sbrana et al. [14] found an unspecific increase in adhesion of monocytes and platelets as a result of non-receptor membrane changes, induced by ECC. Alterations in the RB level were not present. They suggested that the detected IL-10, responsible for monocyte suppression, was released by myocardial lymphocytes. The researchers conducted the examinations with blood from the coronary sinus. That proves the local immunosupp-

Table I. Range and variability of alterations in ROS presentation relying on the basal and fMLP stimulated oxidative burst

\begin{tabular}{|lcccccc|}
\hline Time of measurement & Preoperatively (T1) & $3^{\text {rd }}$ day (T2) & $7^{\text {th }}$ day (T3) & 12 $^{\text {th }}$ day (T4) & 21 $^{\text {st }}$ day (T5) \\
\hline Average \pm SD & $\mathrm{rCL}$ & $1.18 \pm 0.85$ & $1.75 \pm 1.85$ & $1.39 \pm 1.24$ & $0.78 \pm 0.011$ & $0.89 \pm 0.20$ \\
\cline { 2 - 7 } & $\mathrm{pCL}$ & $6.56 \pm 7.69$ & $10.61 \pm 12.3$ & $8.46 \pm 10.50$ & $2.31 \pm 1.45$ & $2.89 \pm 3.12$ \\
\hline Min-max & $\mathrm{rCL}$ & $0.60-3.10$ & $0.70-7.10$ & $0.68-5.33$ & $0.67-1.05$ & $0.62-1.35$ \\
\cline { 2 - 7 } & $\mathrm{pCL}$ & $1.29-22.68$ & $1.21-22.41$ & $1.29-25.29$ & $1.20-6.05$ & $0.89-12.68$ \\
\hline
\end{tabular}

T2, T3, T4, T5 measurements in the postoperative period 
ression. Simultaneously, lack of immunological response suppression, connected with a leukocyte activation decrease, is an unfavorable prognostic factor [15].

Documentary data showed the role of IL- 6 , whose alterations seemed to correlate more specifically with the clinical response to therapy [16]. On the other hand, ECC induces an unspecific increase of IL- 6 with maximal values between postoperative hours 6 and 24 [17]. The superiority of ROS relies on its availability.

Studies were also carried out to assess the role of lipopolysaccharide-binding protein (LBP) in the course of endocarditis. Some results are promising. Wollmer et al. [18] noted high specificity and sensitivity (> 90\%) of this marker. Simultaneously, they estimated the synchrony of LBP and CRP alterations. They confirmed the clinical value of CRP in patients with IE. The LBP showed superiority to CRP only in patients with recurrence of IE during the in-hospital antibiotic therapy. The increase of LBP was observed 3 days prior to the increase of the CRP. According to our results, CRP does not seem to be specific enough for the assessment of a patient with IE and does not show superiority to ESR or WBC. Despite effective therapy it does not normalize in some patients (the median value on the $21^{\text {st }}$ day was $9.3 \mathrm{mg} / \mathrm{l})$. Other researchers did not confirm the diagnostic and prognostic value of LBP, which could be caused by the application of other methods for measurements, as Wollmer suggested. The LBP level was also markedly modified by the surgery. The immediate postoperative period (24-72 h) did not differ in patients with IE or valvular heart disease. In contrast, Ostrowki et al. [19] observed even 3-fold postoperative (on the $3^{\text {rd }}$ day) increase in patients with IE in comparison to patients operated on for valvular diseases. In view of the aforementioned results of Tarnok, postoperative RB stimulation in patients with IE may be related to the release of bacterial antigens. It cannot be excluded that in patients with infection the hyperreactive immune system reacts more extensively to the surgical procedure.

An important issue, demanding an individual clinical approach, is population variability in the response to ECC, reflected by the variable antioxidative capacity (AOC) of the plasma [20]. Unavoidable tissue hypoxia during the operation with subsequent reperfusion increases the production of inflammatory cytokines and ROS [21]. Bugajski et al. [22] observed that hypoxic myocardial cells produce a factor stimulating plasma neutrophils. It was indirectly confirmed to be endothelin 1 . The average time of aortic cross clamping lasting $81 \mathrm{~min}$ allowed us to reduce the ROS alterations modified by hypoxia. Documentary data show that 4-h mild or acute hypoxia markedly affects the ROS value and induces cardioblast apoptosis [23]. In each patient we noted increased ROS generation and analogical time variability, which is a huge advantage in comparison to highly individualized inflammatory markers. A further advantage is its faster normalization in comparison to inflammatory markers (the median on the $12^{\text {th }}$ day vs. the $21^{\text {st }}$ day for WBC, ESR, PCT or CRP). What is more, the ROS content in patients' blood, reflecting the oxidative stress, inflammation advancement or correlating with lipid metabolism, does not undergo such sudden alterations [24]. It would be reasonable to assess ROS only preoperatively, on the $3^{\text {rd }}$ and $12^{\text {th }}$ postoperative day.

Although operative mortality has decreased (30\% in the 1970s), it continues to be high and ranges from $7.5 \%$ to $10 \%$ [25]. In our practice it also reached $10 \%$. Based on the authors' experience and knowledge, only acute mitral and aortic insufficiency in the course of endocarditis demands urgent surgical intervention due to no possibility for compensatory mechanism development and the life-threatening state. According to the newest guidelines, heart failure, uncontrolled infection and prevention of peripheral emboli are the indications for surgery (emergent or urgent) [26].

Surprisingly, no correlation between ROS and PCT was noted. As PCT is a principal marker assessing the bacteremia advancement [27], it should have correlated with ROS and RB, stimulated by the bacterial infection. Probably, the lack of correlation between these parameters is a result of various and sudden kinetics of their alterations. Some authors [17] suggested not determining the absolute values of PCT but following the dynamics of its variability. In our study, comparing the median values from the $7^{\text {th }}$ vs. the $12^{\text {th }}$ postoperative day, we observed a 3-fold decrease of PCT. It should be kept in mind that PCT increases moderately during extensive surgery [27]. This marker, which should achieve normal limits within 2 days on condition of proper antibiotic therapy, is regarded as being more specific and sensitive than CRP, leukocytosis or IL-6 [17, 27]. Our analysis has not confirmed its superiority in patients with IE [28].

The outcomes of our study show the compatibility between ESR, CRP and LBCL variability over time. They also prove the uselessness of the common control of the above two parameters in patients with IE, as was also confirmed by other researchers. They proved mild compatibility between them (67\%) and the superiority of CRP in inflammatory diseases [29]. The correlation between ROS and CRP is not so obvious in the aspect of the mentioned CRP regulative role of leukocyte activation in the infection. This protein takes part in the inhibition of neutrophil chemotaxis and has a slight chemotactic activity on monocytes. Furthermore, it inhibits ROS production, even stimulated by fMLP, which is interpreted as its protective effect on tissues, defending them against oxidative stress [30]. 
On the other hand, it is known to have a negative role in the induction of ROS production by the endothelial progenitor cells, resulting in their increased tendency to apoptosis [31]. The choice of ROS examination seems to be more appropriate also in the view of unspecific CRP, whose increase is observed in burns, myocardial infarction, acute pancreas inflammation, pregnancy, neoplasms, obesity and renal dysfunction [32, 33]. Other studies also confirmed the connection between ROS decrease and patient clinical improvement [19]. The positive correlation between the increase of ROS and the inflammatory markers, found in this study, is indirect evidence of their clinical impact.

The clinical utility of new tests (FORT) assessing the content of ROS in patients' blood was found in myocardial infarction [34]. Their application in patients with endocarditis would be a fast indicator of disease progression.

It should be emphasized that the choice of monitoring parameter depends on the way of treatment: conservative or surgical. It should be included in assessment of inflammatory markers or cytokines. In our opinion ROS level could be a universal indicator, which does not exclude the individualized approach in each episode of IE. The ROS may have a particular implication in high-risk patients, especially when the assays of inflammatory markers are confusing.

Our study has some important limitations. They mainly concern the small number of enrolled patients, which could have disturbed the statistical assessment. However, the number of patients operated on annually for endocarditis in our clinic is 20-30 patients. The purpose of this research was to assess only the most commonly used biochemical markers. These selected markers were also taken into consideration in our previous study [28].

In conclusion, ROS level assessment in patients with IE seems to have wider clinical implications than monitoring inflammatory markers such as WBC, CRP, PCT or ESR. The ROS decrease within the complex treatment of patients with endocarditis was confirmed. Further studies are needed to evaluate the specificity of ROS examination in patients with IE to exclude the marked influence of respiratory hypoxia, obesity, diabetes and other factors inducing RB and also other ways of ROS generation. The contribution of tissue trauma seems to have reduced the impact on the RB and ROS level. FORT application could ensure a rapid, non-invasive, simple and economical indicator in monitoring patients with IE.

\section{Acknowledgments}

This study was supported by the Medical University of Lodz Institutional Grants No. 502-11-206 and 502-11-586.

\section{References}

1. Presterl E, Rokita E, Graninger W, Hirschl AM. Dysregulation of monocyte oxidative burst in streptococcal endocarditis. Eur J Clin Invest 2001; 31: 902-6.

2. Zorov DB, Juhaszova M, Sollott SJ. Mitochondrial ROSinduced ROS release: an update and review. Biochim Biophys Acta 2006; 1757: 509-17.

3. Kawahito K, Kobayashi E, Ohmori M, et al. Enhanced responsiveness of circulatory neutrophils after cardiopulmonary bypass: increased aggregability and superoxide producing capacity. Artif Organs 2000; 24: 37-42.

4. Ryu J, Lee CW, Shin JA, et al. FcgammaRlla mediates C-reactive protein-induced inflammatory responses of human vascular smooth muscle cells by activating NADPH oxidase 4. Cardiovasc Res 2007; 75: 555-65.

5. Hryniewiecki T, Sitkiewicz D, Rawczyńska-Englert I. Role of procalcitonin in the diagnosis of uncomplicated infective endocarditis [Polish]. Przegl Lek 2002; 59: 793-5.

6. Santa Ursula Tolosa JA, Criado A, García del Valle S, Pensado A, Barbolla L, Carmona Aurioles JA. Changes in total and differential leukocyte counts during heart surgery with extracorporeal circulation. Rev Esp Anestesiol Reanim 1991; 38: 94-7.

7. Delogu G, Moretti S, Antonucci A, et al. Apoptosis and surgical trauma. Dysregulated expression of death and survival factors on pheripheral lymphocytes. Arch Surg 2000; 135: 1141-7.

8. Fransen E, Maessen J, Dentener M, Senden N, Geskes G, Buurman W. Systemic inflammation present in patients undergoing CABG without extracorporeal circulation. Chest 1998; 113: 1290-5.

9. Tarnok A, Bosci J, Rossler H, Schlykow V, Shneider P, Hambsch J. Low degree of activation of circulating neutrophils determined by flow cytometry during cardiac surgery with cardiopulmonary bypass. Cytometry 2001; 46: 41-9.

10. Sikora JP, Chlebna-Sokół D, Dąbrowska I, et al. Proinflammatory cytokine innhibitors, TNF-alpha and oxaditave burst of polymorphonuclear leukocytes in the pathogenesis of sepsis in newborn. AITE 2001; 49: 155-61.

11. Grundmann U, Rensing H, Adams HA, et al. Endotoxin desensitization of human mononuclear cells after cardiopulmonary bypass: role of humoral factors. Anesthesiology 2000; 93: 359-69.

12. Volk T, Döpfmer UR, Schmutzler M, et al. Stress induced IL-10 does not seem to be essential for early monocyte deactivation following cardiac surgery. Cytokine 2003; 24: 237-43.

13. Hiesmayr MJ, Spittler A, Lassnigg A, et al. Alterations in the number of circulating leucocytes, phenotype of monocyte and cytokine production in patients undergoing cardiothoracic surgery. Clin Exp Immunol 1999; 115: 315-23.

14. Sbrana S, Bevilacqua S, Buffa M, et al. Post-reperfusion changes of monocyte function in coronary blood after extracorporeal circulation. Cytometry B Clin Cytom 2005; 65: 14-21.

15. Klava A, Windsor AC, Ramsden CW, Guillou PJ. Enhanced polymorphonuclear leucocyte adhesion after surgical injury. Eur J Surg 1997; 163: 747-52.

16. Hryniewiecki T, Rawczyńska-Englert I, Sitkiewicz D, Jabłoński D. Comparison of interleukin-6 and C-reactive protein serum concentrations assessment in diagnosis of infective endocarditis [Polish]. Pol Arch Med Wewn 2002; 108: 947-52. 
17. Sponholz C, Sakr Y, Reinhart K, Brunkhorst F. Diagnostic value and prognostic implications of serum procalicitonin after cardiac surgery: a systemic review of the literature. Crit Care 2006; 10: R145.

18. Vollmer T, Piper C, Kleesiek K, Dreier J. Lipopolysaccharidebinding protein: a new biomarker for infectious endocarditis? Clin Chem 2009; 55: 295-304.

19. Ostrowski S, Kasielski M, Kordiak J, Nowak D. Elevated resting and agonist-induced whole blood chemiluminescence in patients with active infective endocarditis [Polish]. Interact Cardio Vasc Thorac Surg 2009; 8: 12-6.

20. Vogt S, Sattler A, Sirat AS, et al. Different profile of antioxidative capacity results in pulmonary dysfunction and amplified inflammatory response after CABG surgery. J Surg Res 2007; 139: 136-42.

21. Ashkenazi A, Abu-Rabeah K, Marks RS. Electrochemistry and chemiluminescence techniques compared in the detection of NADPH oxidase activity in phagocyte cells. Talanta 2009; 77: 1460-5.

22. Bugajski P, Kalawski R, Baliński M, et al. Plasma-mediated stimulation of neutrophil superoxide anion production during coronary artery bypass grafting: role of endothelin-1. J Thorac Cardiovasc Surg 1999; 47: 144-7.

23. Kolamunne RT, Clare M, Griffiths HR. Mitochondrial superoxide anion radicals mediate induction of apoptosis in cardiac myoblasts exposed to chronic hypoxia. Arch Biochem Biophys 2011; 505: 256-65.

24. Garelnabi MO, Brown WV, Le NA. Evaluation of a novel colorimetric assay for free oxygen radicals as marker of oxidative stress. Clin Biochem 2008; 41: 1250-4.

25. Hanai M, Hashimoto K, Mashiko K, et al. Active infective endocarditis management and risk analysis of Hospital death from 24 years' experience. Circ J 2008; 72: 2062-8.

26. Grupa Robocza Europejskiego Towarzystwa Kardiologicznego (ESC) do spraw zapobiegania, rozpoznawania i leczenia infekcyjnego zapalenia wsierdzia. Wytyczne dotyczące zapobiegania, rozpoznawania i leczenia infekcyjnego zapalenia wsierdzia. (Nowa wersja - 2009) [Polish]. Kardiol Pol 2010; 68 (Suppl. 1): 3-52.

27. Sikora JP, Kwiatkowska R. Clinical usefulness of evaluation of $\mathrm{C}$-reactive protein and procalcitonin concentrations in the diagnosis and monitoring of systemic inflammatory response syndrome [Polish]. Alergia Astma Immunologia 2005; 10: 63-8.

28. Ostrowski S, Nowak D, Marcinkiewicz A, Kasielski M, Zwoliński R, Jaszewski R. Assessment of the surgical treatment of patients with infective endocarditis through observation of alterations in selected inflammatory markers in the postoperative period. Kardiochir Torakochir Pol 2010; 8: 183-90.

29. Colombet I, Pouchot J, Kronz V, et al. Agreement between erythrocyte sedimentation rate and $\mathrm{C}$-reactive protein in hospital practice. Am J Med 2010; 123: 863.e7-13.

30. Mortensen RF, Zhong W. Regulation of phagocytic leukocyte activities by C-reactive protein. J Leukoc Biol 2000; 67: 495-500.

31. Chen J, Huang L, Song M, Yu S, Gao P, Jing J. C-reactive protein upregulates receptor for advanced glycation end products expression and alters antioxidant defenses in rat endothelial progenitor cells. J Cardiovasc Pharmacol 2009; 53: 359-67.

32. Bobilewicz D. Diagnostic role of C-reactive protein (CRP). Przegl Med Laborator 2004; 1: 3-4.

33. Reeves G. C-reactive protein. Aust Prescr 2007; 30: 74-6.

34. Lorgis L, Zeller M, Dentan G, et al. The free oxygen radicals test (FORT) to assess circulating oxidative stress in patients with acute myocardial infarction. Atherosclerosis 2010; 213: 616-21. 